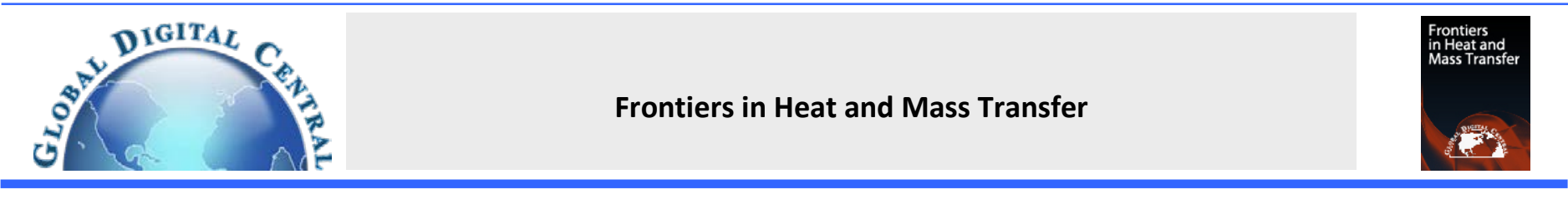

\title{
PREDICTION OF MASS TRANSFER COEFFICIENT OF THE CONTINUOUS PHASE IN A STRUCTURED PACKED EXTRACTION COLUMN IN THE PRESENCE OF SIO2 NANOPARTICLES
}

\author{
Fereshteh Salimi Nanadegani, Bengt Sunden* \\ Department of Energy Sciences, Lund University, SE-22100, Lund, Sweden
}

\begin{abstract}
In this experimental study, mass transfer and hydrodynamic parameters of water/kerosene/acetic acid system in a packed column were investigated, in which the mass transfer direction was set from the continuous phase (saturated water of kerosene and acetic acid) to the dispersed phase (saturated kerosene of water) in all the experiments. To assess the impact of nanoparticles on mass transfer, the experiments were performed in the presence of $\mathrm{SiO}_{2}$ nanoparticles and absence of the nanoparticles. The results showed that the addition of the nanoparticles to the base fluid (saturated kerosene of water) increased the mass transfer efficiency to the critical concentration, $0.05 \mathrm{vol}$. \%, due to the intensified internal circulation of the droplets. Beyond the critical concentration, the mass transfer efficiency declined by the occurrence of an agglomeration phenomenon, i.e., the change of the mass transfer mechanism from turbulence to diffusion due to the accumulation of the nanoparticles. An empirical correlation for the continuous phase Sherwood number was presented. The mean value of the absolute relative error was calculated to $8.04 \%$, indicating that the proposed correlation represented the experimental data very well.
\end{abstract}

Keywords: liquid-liquid extraction, mean droplet diameter, mass transfer direction, mass transfer, regular packed column, nano-fluid.

\section{INTRODUCTION}

Nano-fluids have been recently identified as an excellent medium for heat transfer and mass transfer when nanoparticles are well dispersed in the base fluid (Choi et al. 1995). Adding metallic nanoparticles with high thermal conductivity to a base fluid increases the thermal conductivity of the base fluid. This increase in conductivity depends on factors such as particle shape, particle size, particle volume fraction, and particle aggregation in solution (Xuan and Roetzel, 2000 and Das, 2003).

For convection heat transfer, the heat transfer coefficient depends not only on the thermal conductivity coefficient but also on the density, specific heat, and viscosity of the nano-fluid (Baird and Hamielec, 1962). Wen and Ding (2004) reported that in the range $700<\operatorname{Re}<2000$, heat transfer in the presence of aluminum oxide-water nano-fluid was improved by increasing the concentration of nanoparticles for laminar flow. In Jang and Choi (2004), the effect of $\mathrm{Al}_{2} \mathrm{O}_{3}$ nanoparticles on heat transfer coefficient was investigated. At a volume concentration of $3.0 \%$, the heat transfer coefficient increased by eight times. Ganvir et al. (2017) summarize the current research in the nano-fluid studies on convective heat transfer performance, thermo-physical properties, effect of fluid temperature, inlet velocity, use of surfactant for better stability of nano-fluids, particle size, and volume concentration effects. They showed that the characteristics of the heat transfer of current fluids are improved by suspending nano-sized solid particles with less than $100 \mathrm{~nm}$ in diameter and are considered as prospective working fluids for the applications such as solar collectors, heat pipes, nuclear reactors, electronic cooling systems, automobile radiators etc.

The impact of nanoparticles on mass transfer performance was considered by researchers including Kang and Kim (2006) and Olle et al. (2006). The mechanism of increasing the mass transfer in the presence of nanoparticles has not been observed well due to the lack of empirical data. Still many researches and experiments are needed to determine effective factors. Influential forces such as weight, buoyancy, and drag lose their impact by decreasing the size of the particles taking into account nano-size. However, special features such as high specific surface level, mobility, and speed of particles increase. High mobility of nanoparticles leads to the Brownian motions, which enhances convection heat transfer and thermal conductivity (Prasher, 2005) Considering the similarity in heat transfer and mass transfer (Eckert et al., 2001), the impact of aluminum oxide-water nano-fluid was studied by the influence of color by taking time-dependent images (Krishnamurthy et al., 2006). They observed that the penetration rate in nano-fluids is more than in distilled water (base fluid), and the highest penetration occurs at $0.5 \%$ volume concentration of nanoparticles. Based on the displacement mean equation, in fact, the Brownian motion of nanoparticles is not directly effective in improving the penetration coefficient, but the random speed field created by the Brownian motion of nanoparticles is the main reason of the increase in penetration coefficient.

Kim et al. (2006) used nano-fluids to improve the gas absorption in $\mathrm{NH}_{3} / \mathrm{H}_{2} \mathrm{O}$ system. They used $\mathrm{Cu}, \mathrm{CuO}$, and $\mathrm{Al}_{2} \mathrm{O}_{3}$ nanoparticles in the base fluid. They observed that bubbles generated in the nano-fluid are smaller than for the fluid without nanoparticles, attributing it to collisions of nanoparticles with the generated bubbles. This collision increases the mass transfer surface, so bubbles are absorbed faster in a nano-fluid. They also found that the maximum effective absorption ratio is 3.21 at an ammonia concentration $18.7 \%$ and volume fraction 0.1 (0.1 vol. \%) of Cu nanoparticles. Zhu et al. (2009) investigated the effect of the aluminum oxide nanoparticles on the thermal conductivity of water in various concentrations of surfactants (SDBS) and different pHs. They examined the concentration of nanoparticles and concentration of surfactant (SDBS) as key parameters, revealing that the thermal conductivity increased $10.1 \%$ at a weight concentration of $0.15 \%$. According to their results, the highest thermal conductivity occurred at $\mathrm{pH} 8$.

*Corresponding author. E-mail; bengt.sunden@energy.lth.se 
In many studies (Yang et al, 2005, Chen et al., 2008, Garg et al., 2009), it was observed that the performance of heat transfer increases significantly in nano-fluids compared to pure fluids. Lee et al. (2011) conducted carbon dioxide absorption operations, using a bubble tower, methanol as the base fluid, and nanoparticles $\mathrm{Al}_{2} \mathrm{O}_{3}$ and $\mathrm{SiO}_{2}$. They could increase the absorption of $\mathrm{Al}_{2} \mathrm{O}_{3}$ nano-fluid by $4.5 \%$ at a concentration of $0.01 \%$ and for $\mathrm{SiO}_{2}$ by $5.6 \%$ at a concentration of $0.05 \%$. They also obtained an optimum volume concentration of $0.01 \%$ for each nanoparticle. After this, the optimum concentration of the mass transfer rate was reduced. They stated the decline was due to sticking of the nanoparticles and reduction of Brownian motion (agglomeration phenomenon). The impact of nanoparticles on hydrodynamic characteristics and the rate of mass transfer of pulsed packed columns were studied by Bahmanyar et al. (2011). To prepare nano-fluids with concentrations of $0.01,0.05$, and 0.1 , they dispersed $\mathrm{SiO}_{2}$ nanoparticles in a kerosene base fluid saturated with distilled water by an ultrasonic device. They observed that the rate of mass transfer was improved by 4-60\%. Manikandan et al. (2012) examined the effect of $\mathrm{Fe}_{2} \mathrm{O}_{3}$-water nano-fluid on oxygen absorption mass transfer coefficient from air bubbles in an agitated aerated bioreactor. The results showed that the mass transfer coefficient at a concentration of 0.065 wt. \% increased by $63 \%$ at $200 \mathrm{rpm}$ and an air flow rate of $0.75 \mathrm{~mL} / \mathrm{min}$.

$\mathrm{Lu}$ et al. (2013) observed the increase of $\mathrm{CO}_{2}$ absorption in the presence of $\mathrm{Al}_{2} \mathrm{O}_{3}$ and carbon nanotube (CNT) nanoparticles. They conducted carbon dioxide absorption in a stirring thermostatic reactor. According to their results, the mass transfer rate increased in the presence of these nanoparticles. By increasing the size of microparticles, the mass transfer rate declined. In another work, Bahmanyar et al. (2014) studied the effect of $\mathrm{SiO}_{2}$ nanoparticles on mass transfer in pulsed packed columns and provided a new empirical equation for prediction of the effective penetration and mass transfer coefficient. Accordingly, the mass transfer performance improved by $60 \%$ at $0.1 \%$ volume concentration. Ashraf Mansouri et al. (2015) studied the impact of nano- $\mathrm{SiO}_{2}$ on hydrodynamics and mass transfer of spray liquid-liquid extraction columns with a chemical system of toluene/acetic acid/water. Total mass transfer coefficient and extraction efficiency increased by $47 \%$ and $26 \%$, respectively, in the presence of $\mathrm{SiO}_{2}$ nanoparticles at a volume concentration of $0.001 \%$. In fact, they attributed the improvement of the mass transfer coefficient and the extraction efficiency to the Brownian motion of larger droplets and internal rotations. They also stated the cause of the reduction in the mass transfer coefficient and the extraction efficiency was an agglomeration of nanoparticles. Reza Mohammadi et al. (2015) evaluated the impact of $\mathrm{SiO}_{2}$ nanoparticles, mass transfer, and pulse severity on specific speed in regular pulsed packed columns and provided a new empirical equation for the specific speed. Based on their findings, in water-kerosene systems and water-acid acetickerosene systems, there is a critical value, $1.2 \mathrm{~cm} / \mathrm{s}$, for the pulse intensity. At low pulse intensities, the specific speed decreases due to the reduction of the size of the droplets, and the specific speed increases at higher pulse intensities. They observed that the mass transfer increased the specific speed. Their experiments showed that in the presence of nanoparticles, due to the increase in average droplet diameter and Brownian motion, droplets capability regarding failure increased; by the increase of pulse intensity, the specific speed decreased steadily. In another work, Hosseini Moghadam et al. (2017) investigated the effect of nanoparticles on mass transfer coefficient. For this purpose, kerosene saturated with water, water saturated with kerosene and acetic acid were used as the dispersed phase, continuous phase, and solute, respectively. The nanofluids used were prepared by dispersing $\mathrm{SiO}_{2}$ nanoparticles of 0.01, 0.05 and 0.1 vol\% in dispersed phase as base fluid employing ultrasonic technic. The effect of three different size silica nanoparticles ranged within 11-14, 20-30 and 60$70 \mathrm{~nm}$, on the hydrodynamic and mass transfer of circulating drops in liquid-liquid extraction was investigated by Saien and Hasani (2017). They used chemical system of toluene-acetic acid-water. They found that he viscosity of nanofluids increases slightly with the size and concentration of the nanoparticles whereas the system interfacial tension remains almost constant. Terminal velocity values were comparable with those predicted by Grace and Vignes equations.

Hatami et al. (2017) used the chemical system of toluene, acetic acid, and water, and the direction of solute (acetic acid) mass transfer was from the dispersed phase, including toluene and acetic acid to the continuous phase of water. For such a system, much of the mass transfer resistance exists in the dispersed phase, which is a nonpolar organic liquid. Hence, modified titania nanoparticles (MTNP's), prepared by the sol-gel route, in five different concentrations of $0.001-$ 0.005 wt.\% were added in the dispersed phase. Results indicated an anomalous enhancement in the overall dispersed-phase mass transfer coefficient at 0.002 wt.\% of MTNP's. A maximum enhancement of $70 \%$ in the overall mass transfer coefficient was found in droplets formed from a nozzle of $2.5 \mathrm{~mm}$ inner diameter, containing $3 \mathrm{wt}$ \% of solute. Eventually, based on the theoretical model of Newman, a semiempirical model was presented, that is capable to predict the overall dispersed-phase mass transfer coefficient of nanofluids with an average absolute relative error of 8.6\%. The influence of different $\mathrm{ZnO}$ nanoparticle concentrations (0.001, 0.003, 0.005 and $0.01 \mathrm{wt} \%)$ along with operating parameters (i.e., pulsation intensity and flow rate of dispersed and continuous phases) and physical properties on mean drop size and drop size distribution in a horizontal pulsed perforatedplate extraction column for the toluene-acetone-water and butyl acetate-acetone-water systems (mass transfer direction from the dispersed phase to the continuous phase) were investigated by Amani et al. (2017). They were observed that the addition of nanoparticles has a remarkable influence on breakage and coalescence of drops and consequently their size distribution. Accordingly, adding nanoparticles reduces the interfacial tension due to internal turbulence caused by nanoparticles' Brownian motion inside each drop. It is found that drop size distribution will shift to the left and the density of small droplets will increase in the presence of $\mathrm{ZnO}$ nanoparticles in the column. Furthermore, a new correlation is proposed to predict mean drop size in terms of operating parameters, physical properties, and nanoparticle concentration. It is also found that the maximum entropy principle is suitable to predict drop size distribution in a horizontal extraction column. Saien and Daneshamoz (2018) were investigated the influence of ultrasonic waves on liquid-liquid extraction of circulating drops and in the presence of magnetite nanoparticles. Their innovative study highlights the fact that using ultrasonic waves is an interesting way to improve liquid-liquid extraction in the presence and absence of nanoparticles.

The rate of $\mathrm{CO}_{2}$ mass transfer into various nanofluids in two different systems (packed bed column and hollow fiber membrane) has been predicted using an adaptive neuro-fuzzy inference system (ANFIS) by Zarei et al (2018). Various effective parameters including nanoparticle diameter, nanoparticle concentration, liquid flow rate, gas flow rate and $\mathrm{CO}_{2}$ inlet concentration have been chosen as input variables. Moreover, in order to investigate the type of nanoparticle effect on the mass transfer rate, the density of nanoparticles is 
considered as an input for the ANFIS model. They proved the ANFIS model is capable of predicting the $\mathrm{CO}_{2}$ mass transfer rate into all of the nanofluids precisely two distinct absorption systems, including packed bed column and hollow fiber membrane. Rafiei et al. (2018) proposed a new empirical correlation for the prediction of the overall continuous phase Sherwood number based on the Reynolds number, the Schmidt number, and the values of the holdup, denoting a satisfactory agreement with the experimental data. Azimi et al. (2019) investigated the effect of high-frequency ultrasound propagation in a sono-extractor to augment liquid-liquid mass transfer in the presence of $\mathrm{SiO} 2$ nanoparticles. They found that Using ultrasound and nanoparticles showed a higher effect on the increase in the mass transfer characteristics compared with only using ultrasound or nanoparticles.

In some works, mass and heat transfer were investigated for new patterns of flow. Using of microfluidic devices for the extraction of oleuropein from ethyl acetate into the aqueous phase was investigated by Naleini et al. (2015). The results illustrate that the proposed technique has some advantages compared with other methods including, the simplicity of operation, cost-effective, and environmentally friendly. Doherty et al. (2017) were designed a device to test the behavior of airflow with non-isothermal boundary conditions within a rectangular cavity. Dharmaiah et al. (2018) were carried out a numerical investigation to analyze the unsteady, twodimensional, laminar, boundary layer flow of a viscous incompressible electrically conducting and heat-absorbing fluid along with a semiinfinite vertical permeable moving plate in the presence of DiffusionThermo and radiation absorption effects. Mohammad (2020) was performed an analysis to study the effects of variable viscosity on steady, laminar, hydromagnetic simultaneous heat and mass transfer by mixed convection flow along a vertical cylinder embedded in a nonDarcy porous medium. It found that increasing the values of the powerlaw index, curvature parameter, and buoyancy ratio lead to enhance local Nusselt and Sherwood numbers. The local Nusselt and Sherwood numbers weaken as the inertia effect parameter and the square of the Hartmann number increases. The rise in the value of the Lewis number decreases the rate of heat transfer while increases the rate of mass transfer. For lower values of viscosity, the heat transfer increased for both gases and liquids, while the mass transfer decreased for gases and increased for liquids.

Many researchers, including Griffith (1960), Lochiel and Calderbank (1964), Brauer and Mewes (1971), Weber (1975), and Clift et al. (1978) measured the continuous phase Sherwood number in different columns (except for the packed columns) and presented relationships for the Sherwood number of the continuous phase based on static droplet, rotational droplet, and oscillating droplet. The relationship provided for the continuous phase Sherwood number in packed columns presented by Siebert and Fair (1988) reads as Eq. (1):

$$
S h_{c}=0.698 R e^{0.5} S c_{c}{ }^{0.4}(1-\varphi)
$$

where $\mathrm{Sh}_{\mathrm{c}}, \mathrm{Re}, \mathrm{SC}_{\mathrm{c}}$, and $\varphi$ are continuous phase Sherwood number, Reynolds number, continuous phase Schmidt number and dynamic holdup, respectively.

Rahbar-Kelishami and Bahmanyar (2012), examined the toluene/ acetic acid/ water systems and n-butyl acetate/ acetic acid/ water, and they presented Eq. (2) for the continuous phase Sherwood number.

$$
S h_{c}=-55.6+6.21 \times 10^{-5} R e^{0.433} S c_{c}^{2.26}\left(\frac{d_{32}}{h}\right)^{0.4}
$$

In this relationship, a dimensionless parameter $\frac{\mathrm{d}_{32}}{\mathrm{~h}}$ is introduced. It shows the impact of column height and mean diameter of droplets. This parameter indicates that with increasing droplet size by increasing the internal rotations, the rate of mass transfer increases, so $\mathrm{Sh}_{\mathrm{c}}$ increases. In addition, are increase of the filler height reduces $\mathrm{Sh}_{\mathrm{c}}$.

In the present experimental study, mass transfer and hydrodynamic parameters of water/kerosene/acetic acid system in a packed column are investigated. The mass transfer direction is set from the continuous phase (saturated water of kerosene and acetic acid) to the dispersed phase (saturated kerosene of water) in all the experiments. Based on the experiments a correlation is proposed. It has good accuracy due to the increased internal circulation of the droplets by the addition of nanoparticles.

\subsection{Column set-up}

\section{EXPERIMENTAL}

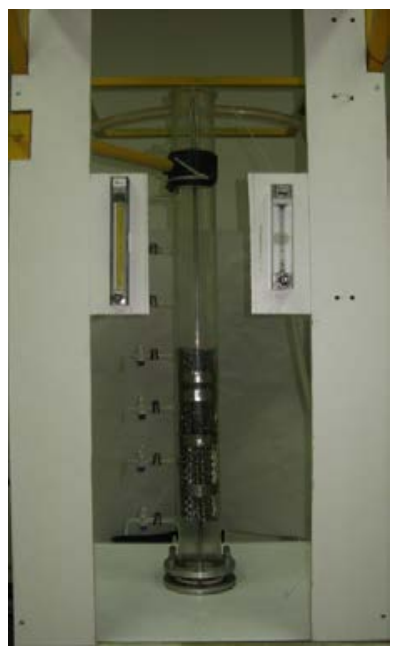

(a)

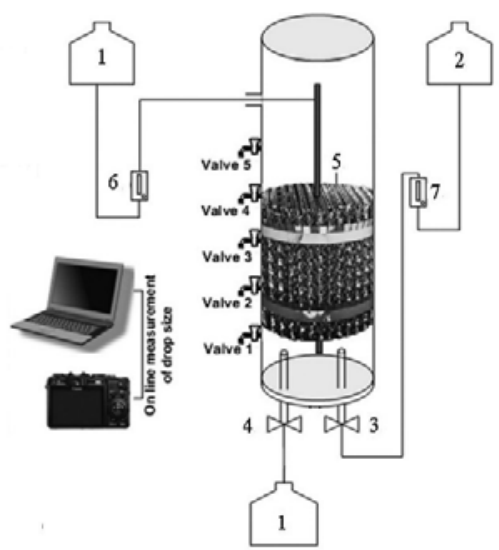

1. Continuous phase container

2. Dispersed phase container

3. Continuous phase nozzle

4. Dispersed phase nozzle

5. Packing

6. Continuous phase flow meter

7. Dispersed phase flow meter

(b)

Fig. 1 (a) Experimental set-up, (b) schematic diagram of the apparatus

A schematic picture of the used packed column is presented in Fig. 1 (Tests were conducted in Liquid-liquid Extraction Research Laboratory, University of Tehran, Tehran, Iran). The packed column was made of Pyrex glass with inside diameter of $9.1 \mathrm{~cm}$ and $125 \mathrm{~cm}$ height filled with regular packing and made of stainless steel (PentaPak TM PS-500M1), with $40 \mathrm{~cm}$ height (Table 1). The water required for the tower (continuous phase) was stored in a container. Water enters through a flow control valve and a nozzle at the top of the column. The flow rate of the continuous phase remained constant at 60 
$\mathrm{mL} / \mathrm{min}$ and was controlled by a rotameter. The dispersed phase was stored in a tank installed above the column. The dispersed phase moves to the bottom of the column through two nozzles with interior diameters of $1 \mathrm{~mm}$ (for the ultrafine droplets regime) and $2.5 \mathrm{~mm}$ (for the single drop regime). There is an outlet valve at the bottom of the column to discharge the continuous phase at the end of each experiment. A camera 14 MPixel, Canon, Model SX210 was used to take photos from drops above the nozzle to calculate the mean droplet diameter.

Table1

Specification of pulsed packed column and range of operating variables.

\begin{tabular}{ll}
\hline Material of construction for the column & Pyrex \\
\hline The height of column & $125 \mathrm{~cm}$ \\
\hline Inner diameter of the column & $9.1 \mathrm{~cm}$ \\
\hline The distance between two adjacent valves & $14 \mathrm{~cm}$ \\
\hline The height of the packed section & $40 \mathrm{~cm}$ \\
\hline The porosity of packing & 0.94 \\
\hline The surface area of packing & $500 \mathrm{~m}^{2} / \mathrm{m}^{3}$ \\
\hline
\end{tabular}

\subsection{Chemical system}

The chemical system studied was kerosene - acid acetic- water (K/A/W). The continuous phase was saturated water with acid acetic ( 2 vol. \%), and the saturated kerosene composed the dispersed phase. Nano-fluids were prepared by dispersing hydrophobic nanoparticles $\mathrm{SiO}_{2}$, supplied by Wacker-Chemistry Company Germany (HDK $\mathrm{H}_{2} \mathrm{O}$ ), into the base fluid (saturated kerosene of water). A Hielscher ultrasound generator ( $24 \mathrm{kHz}, 400 \mathrm{~W}$ ) was used to ensure the stability of the nano-fluid for 1 hour (using H14 sonotrode with $125 \mu \mathrm{m}, 105$ $\mathrm{W} / \mathrm{cm}^{2}$, and $0.7 \mathrm{~s}$ pulse duration). The nano-fluid was utilized as the dispersed phase after reaching ambient temperature. The nanoparticles were in the range of 5-30 nm and density of $2200 \mathrm{~kg} / \mathrm{m}^{3}$. Interfacial tension and viscosity were measured with a Digital Tensiometer K10ST and a Visco Clock, respectively. Experiments were done at three different volumetric percentages $(0.01,0.05$, and 0.10 vol. \%). Table 2 shows the physical properties of the used chemical system.

Table 2

Physical properties of systems at $20^{\circ} \mathrm{C}$.

\begin{tabular}{llllll}
\hline $\begin{array}{l}\text { Continuous } \\
\text { phase }\end{array}$ & $\begin{array}{l}\text { Dispersed } \\
\text { phase }\end{array}$ & $\begin{array}{l}\mu_{\mathrm{c}} \\
(\mathrm{mPa} \mathrm{s})\end{array}$ & $\begin{array}{l}\mu_{\mathrm{d}} \\
(\mathrm{mPa} \mathrm{s})\end{array}$ & $\begin{array}{l}\rho_{\mathrm{c}} \\
\left(\mathrm{kg} / \mathrm{m}^{3}\right)\end{array}$ & $\begin{array}{l}\rho_{\mathrm{d}} \\
\left(\mathrm{kg} / \mathrm{m}^{3}\right)\end{array}$ \\
\hline SW $^{\mathrm{a}-A A^{\mathrm{b}}}$ & $\mathrm{SK}^{\mathrm{c}}$ & 0.87 & 1.13 & 999 & 785 \\
\hline SW-AA & $\begin{array}{l}\mathrm{SK}+0.01 \mathrm{vol} \% \\
\mathrm{HDK} \mathrm{H}_{2} \mathrm{O}\end{array}$ & 0.87 & 1.25 & 999 & 788 \\
\hline SW-AA & $\begin{array}{l}\mathrm{SK}+0.05 \mathrm{vol} \% \\
\mathrm{HDK} \mathrm{H}_{2} \mathrm{O}\end{array}$ & 0.87 & 1.33 & 999 & 790 \\
\hline SW-AA & $\begin{array}{l}\text { SK+0.10vol\% } \\
\mathrm{HDK} \mathrm{H}_{2} \mathrm{O}\end{array}$ & 0.87 & 1.70 & 999 & 792 \\
& & & & & \\
\hline $\begin{array}{l}{ }^{a} \text { SW: saturated water } \\
\text { bAA: 2vol\% acetic acid } \\
\text { cSK: saturated kerosene }\end{array}$ & & & & \\
\hline
\end{tabular}

\subsection{Procedure}

Prior to the experiments, the column and all other equipment were cleaned with deionized water. At the beginning, two phases (continuous and dispersed) were mutually saturated before being applied in the experiments. In the next step, the column was filled up to the packing (interface) with the continuous phase. The flow rate of the inlet and outlet continuous phase was fixed to the specific amount of $60 \mathrm{~mL} / \mathrm{min}$ and change by a flow meter. The flow rates of the dispersed phase were fixed to 40,60, and $80 \mathrm{~mL} / \mathrm{min}$ and change by a flow meter. Experiments were done at three different volumetric percentages of nanoparticles $(0.01,0.05$, and 0.10 vol. \%). Photographs were taken from drops above the nozzle, after getting the steady rate using a Canon digital camera. Dimensions of the droplets (taken as the diameter for spherical droplets and average of the minor and major axis for ellipsoidal droplets) were determined at each step using the AutoCAD software.

When the system reached steady state, the sample was taken from the dispersed and continuous phase at different heights of the column $(11,25,39 \mathrm{~cm})$ in the presence of nanoparticles as well as their absence to investigate mass transfer through the sampling valve. Once the samples were collected in two phases, 5 cc of the dispersed phase is separated by a decanter and analyzed by titration with a Strong Base; $0.1 \mathrm{~N}$ Sodium Hydroxide (NaOH) to determine the concentration of acetic acid present in the sample. The Endpoint of the Titration will be detected using a Phenolphthalein indicator.

At the end of each test, the shutdown method was used for measuring holdup. In the shutdown method, after reaching steady conditions, the flow rates of the inlet and the outlet of the continuous phase and dispersed phase were closed at the same time. The coalescence for the dispersed phase moving inside the packed column can occur at the interface. The interface height change was measured.

The mass transfer occurred from the continuous to the dispersed phase and due to slight changes in temperature laboratory, experiments were performed at $25^{\circ} \mathrm{C}$ to neglect its effect on the mass transfer.

\subsection{Calculation of the Sauter diameter}

The Sauter diameter was used to approximate the mean diameter of droplets as the drop size is non-uniform in the extraction columns. A Canon 14 Mpixel, model SX210 camera was used to take photos from drops above the nozzle. The Auto CAD software was used to obtain the mean droplet diameter (Sauter diameter), and it is calculated by Eq. (3).

$$
d_{32}=\frac{\sum_{i=1}^{N} n_{i} d_{d i}^{3}}{\sum_{i=1}^{N} n_{i} d_{d i}^{2}}
$$

where $\mathrm{n}$ is the number of droplets, $\mathrm{d}_{\mathrm{d}}$ drop diameter and $\mathrm{N}$ total number of the experiment.

\subsection{Calculation of the mass transfer coefficient}

Mass transfer coefficient is one of the most important parameters in design and choice of optimal conditions of liquid-liquid extraction. The Eq. (4) was used to calculate the mass transfer coefficient based on mass balance for a single drop.

$$
K_{d}\left(C_{d}^{*}-C\right) \times 4 \pi r^{2}=\frac{4}{3} \pi r^{3} \frac{d c}{d t}
$$
(5).

By integrating Eq. (4), the solution for $K_{d}$ can be written as in Eq.

$$
K_{d}=-\frac{d_{32}}{6 t} \ln (1-E)
$$

where $\mathrm{E}$ is the extraction efficiency, see below. $\mathrm{t}$ denotes the mean rising time defined in Eq. (6).

$$
t=\frac{L \varepsilon \varphi_{d} A}{Q_{d}}
$$

where $\mathrm{L}, \varepsilon, \mathrm{A}$ and $\mathrm{Q}_{\mathrm{d}}$ are dynamic column height, the porosity of porous media, surface area and flow rate of the continuous phase, respectively. In addition, $\varphi_{\mathrm{d}}$ is the dynamic holdup calculated as Eq. (7):

$$
\varphi_{d}=\frac{V_{d}}{V_{d}+V_{c}}
$$


where $V_{d}$ and $V_{c}$, respectively, are dispersed phase velocity and continuous phase velocity given by Eqs. (8) and (9).

$$
\begin{aligned}
V_{d} & =\frac{Q_{d}}{A} \\
V_{C} & =\frac{Q_{C}}{A}
\end{aligned}
$$

E designates the extraction efficiency defined by Eq. (10):

$$
E=\frac{C_{0}-C}{C_{0}-C_{d}^{*}}
$$

where $\mathrm{C}_{\mathrm{o}}$, $\mathrm{C}$, and $\mathrm{C}_{d}^{*}$ are, respectively, the initial concentration of solute in the continuous phase, solute concentration in the dispersed phase at the specified height and solute concentration in the dispersed phase in equilibrium with the continuous phase.

Assuming no-resistance for mass transfer at the interface between the two phases, Eq. (11) gives the relation between $K_{c}$ (the mass transfer coefficient of the continuous phase) and $\mathrm{K}_{\mathrm{d}}$ (the mass transfer coefficient of the dispersed phase) (Annesini et al., 2017).

$$
K_{d}\left(C_{d}{ }^{*}-C\right)=K_{c}\left(C_{c}-C_{c}{ }^{*}\right)
$$

where $\mathrm{C}_{\mathrm{c}}$ and $\mathrm{C}_{c}^{*}$ are the solute concentration in the continuous phase at the specified height and solute concentration in the continuous phase in equilibrium with the dispersed phase, respectively.

\subsection{Calculation of Sherwood number of the continuous phase}

The Sherwood number of the continuous phase depends on different parameters such as the drop mean diameter, the slip velocity, the density, the interfacial tension, and the diffusion coefficient. The Eq. (12) was used to calculate the Sherwood number.

$$
S h_{C}=\frac{K_{c} d_{32}}{D_{c}}
$$

where $D_{c}$ is the diffusion coefficient of the continuous phase.

Absolute relative error values (ARE) and average absolute relative error values (AARE) will be used to compare experimental values with the results from the suggested correlation (Eq.15). ARE and AAEE are calculated by Eqs. (13) and (14), respectively.

$$
A R E=\frac{\text { Predicted value }- \text { Experimental value }}{\text { Experimental value }}
$$

$A A R E$

$$
=\frac{1}{N} \sum_{i=1}^{N} \frac{\text { Predicted value }- \text { Experimental value }}{\text { Experimental value }}
$$

\subsection{Mean droplet diameter}

As the nozzle diameter increases, the droplet diameter increases, and the interfacial area of the drops with the continuous phase decreases, but the rotation in the drops becomes larger and larger. This result agrees with (Hayworth and Treybal, 1950). Fig. 2 indicates that the inclusion of nanoparticles by $0.01 \mathrm{vol}$. \% would increase the Brownian motion and the droplet diameter.

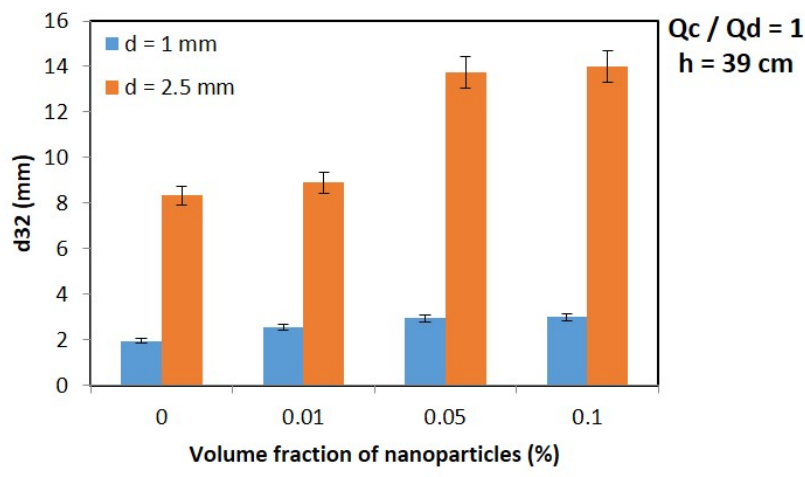

Fig. 2 Effect of presence of nanoparticles on mean droplet diameter.

\subsection{Extraction efficiency}

Fig. 3 depicts the effect of concentration of nanoparticles on the extraction efficiency. In a nozzle with $1 \mathrm{~mm}$ hole-diameter, by addition of nanoparticles to a certain concentration, $0.05 \mathrm{vol}$. \%, the extraction efficiency increases as a result of the increasing of droplets' diameter and Brownian motion due to the increased internal rotation. By adding nanoparticles to the dispersed phase, and if the concentration of the nanoparticles is above a critical volume, (identified as 0.10 vol. \%), coalescence occurs among the nanoparticles, and they act as inhibitors for the diffusion and hinder the movement of the solute component. Thus, internal rotation reduces the extraction efficiency. Therefore, the critical concentration for this nozzle is set at $0.05 \mathrm{vol}$. \%. This is in agreement with the results of many authors (Krishnamurthy et al, 2006, Fang et al., 2009, Gerardi et al., 2009, Veilleux et al., 2010, Ashrafmansouri et al., 2016). Their results show the Brownian motion of nanoparticles and induced micro convection might be responsible for observing mass transfer enhancements at low concentrations of nanoparticles (Krishnamurthy et al, 2006, Veilleux et al., 2010). In addition, nanoparticle aggregation and hindered diffusion (friction with nanoparticle aggregates) of the solute might be responsible for the deteriorated mass transfer at higher nanoparticle concentrations Fang et al., 2009, Gerardi et al., 2009].

In a nozzle with $2.5 \mathrm{~mm}$ hole-diameter, by addition of nanoparticles to $0.01 \mathrm{vol}$. \%, the efficiency increases as a result of the increased Brownian motion. The probable reason is that a smaller diameter and lower internal turbulence of the drops increase the dispersed phase resistance potential to be manipulated by the Brownian motion of nanoparticles (Ashrafmansouri and Nasr Esfahany, 2016). Due to the continuous increase of the extraction efficiency in the concentration range of nanoparticles, added, critical levels were not found for the 2.5 mm nozzle.

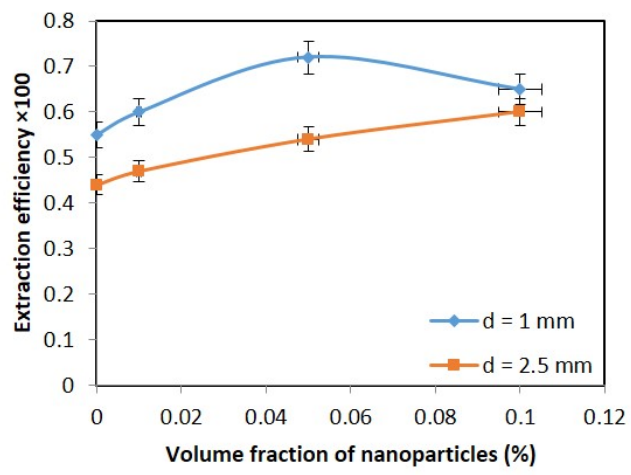

$\mathrm{Qc} / \mathrm{Qd}=1$ $\mathrm{h}=39 \mathrm{~cm}$

Fig. 3 Effect of presence of nanoparticles on mass transfer efficiency. 


\subsection{Mass transfer coefficient}

Fig. 4 shows that in a nozzle with a $1 \mathrm{~mm}$ hole-diameter, with the addition of nanoparticles to a certain concentration, 0.05 vol. \%, the Brownian motion overcomes the increase in internal rotation on reducing the mass transfer surface area and the mass transfer coefficient increases. Then, by adding nanoparticles to the dispersed phase, and if the concentration of the nanoparticles is above a critical concentration, identified as $0.10 \mathrm{vol}$. \%, the mass transfer coefficient declines by the occurrence of an agglomeration phenomenon, i.e., the change of mass transfer mechanism from turbulence to diffusion as the nanoparticles are accumulated. In a nozzle with a $2.5 \mathrm{~mm}$ holediameter, by the addition of nanoparticles to 0.01 vol. \%, the effective mechanisms are internal rotation and the mass transfer coefficient increases as a result. In addition, due to the small average droplet size and reduction in internal rotation, the nozzle of $1 \mathrm{~mm}$ in comparison with the nozzle of $2.5 \mathrm{~mm}$, has less mass transfer coefficient. In another work (Nematbakhsh and Rahbar-Kelishami, 2015) with mass transfer direction from the dispersed phase to the continues phase, it was also observed, that the mass transfer coefficient of the dispersed phase increases and reaches a peak by adding nanoparticles. This behavior has been attributed to micro-convection induced directly by Brownian motion inside the base fluid.

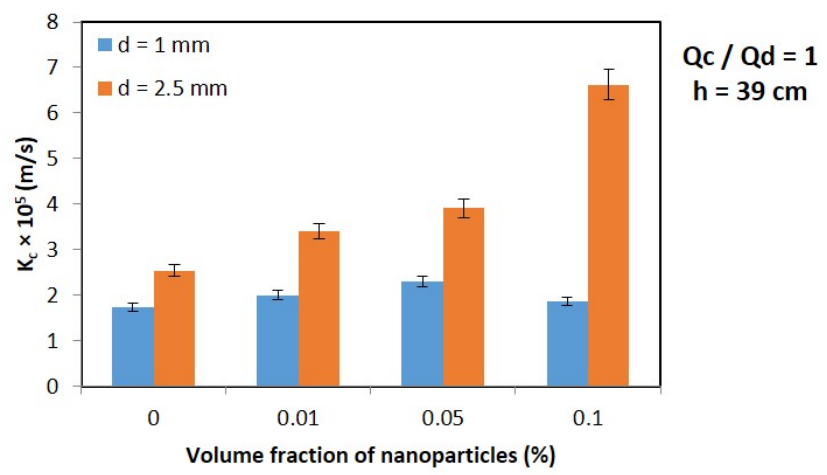

Fig. 4 Effect of presence of nanoparticles on mass transfer coefficient.

\section{SUGGESTION OF A NEW CORRELATION FOR THE SHERWOOD NUMBER OF CONTINUOUS PHASE}

Experimental results showed that the following parameters affect the Sherwood number of the continuous phase and the mass transfer coefficient of the continuous phase.

\subsection{The mean droplet diameter $\left(d_{32}\right)$}

The mean droplet diameter $\left(\mathrm{d}_{32}\right)$ is directly proportional to the mass transfer coefficient of the drop. By the addition of nanoparticles, the mean droplet diameter increases. The internal circulation of the drops increases with the drop size; hence, the mass transfer coefficient increases.

\subsection{The height of the packed section (h)}

According to the Figs. 5 and 6, the height of the packed section (h) is inversely proportional to the mass transfer coefficient; hence, the driving force for the mass transfer (the concentration difference) decreases with the parameter h. Thus, the mass transfer rate diminishes.

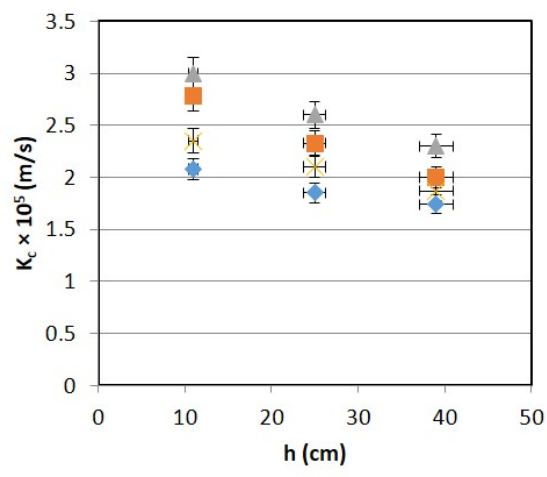

Qc $/ \mathrm{Qd}=1$

$\mathrm{d}=\mathbf{1} \mathrm{mm}$

- 0.00 Vol\% nanoparticle 0.01 Vol\% nanoparticle 0.05 Vol\% nanoparticle 0.10 Vol\% nanoparticle

Fig. 5 Effect of the height of the packed section (h) on mass transfer coefficient $(\mathrm{d}=1 \mathrm{~mm})$.

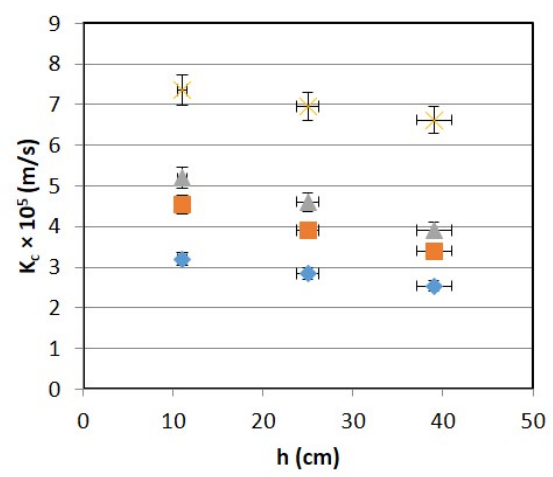

$$
\text { Qc / Qd = } 1
$$$$
\mathrm{d}=2.5 \mathrm{~mm}
$$

\section{Vol\% nanoparticle}

0.01 Vol\% nanoparticle

$\triangle 0.05$ Vol\% nanoparticle

0.1 Vol\% nanoparticle

Fig. 6 Effect of the height of the packed section (h) on mass transfer coefficient $(\mathrm{d}=2.5 \mathrm{~mm})$.

\subsection{The flow rate ratio $\left(Q_{d} / Q_{d}\right)$}

As depicted in Figs. 7 and 8, the flow rate ratio $\left(Q_{d} / Q_{d}\right)$ is directly proportional to the mass transfer coefficient of the drops. By increasing the flow rate of the dispersed phase, the flow rate ratio of the continuous phase to the dispersed phase is decreased. By reducing the size of the droplets, the dynamic holdup and mass transfer resistance increased (lower mass transfer driving force), and as a result, the mass transfer decreased. In (Hashem and Aimaghrabi, 2013) it was also observed that the mass transfer coefficient increases with increasing the continuous phase flow rate and decreases with increasing the dispersed phase flow rate.

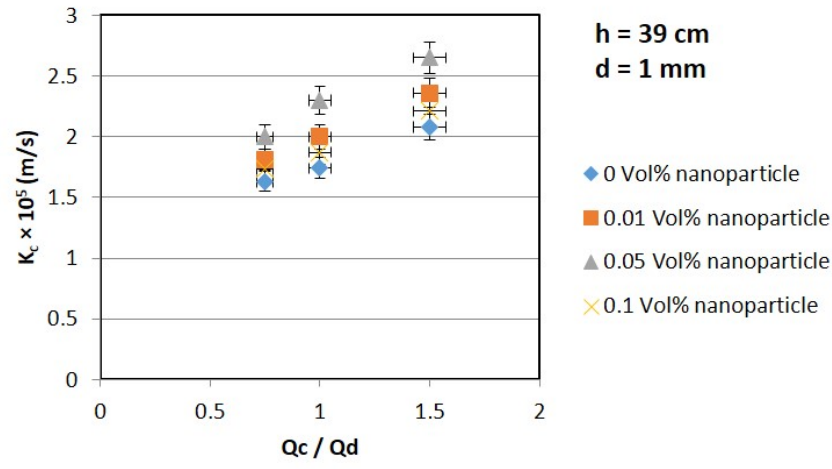

Fig. 7. Effect of the flow rate ratio $\left(Q_{c} / Q_{d}\right)$ on mass transfer coefficient $(d=$ $1 \mathrm{~mm})$. 


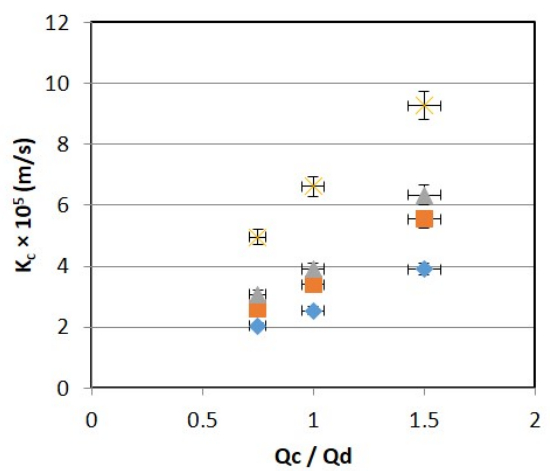

$\mathrm{h}=39 \mathrm{~cm}$

$\mathrm{d}=2.5 \mathrm{~mm}$

0 Vol\% nanoparticle

0.01 Vol\% nanoparticle

$\triangle 0.05$ Vol\% nanoparticle

0.1 Vol\% nanoparticle

Fig. 8. Effect of the flow rate ratio $\left(Q_{c} / Q_{d}\right)$ on mass transfer coefficient $(d=$ $2.5 \mathrm{~mm})$.

According to the aforementioned parameters and considering the available correlations for the Sherwood number of the continuous phase and according to data from 72 experiments conducted, the following correlation was presented. The constants were tuned by the EViews software package:

$$
\begin{gathered}
S h_{c}=0.82\left(P e_{c}\right)^{1.89}\left[\left(\frac{3 \times 10^{-8}}{1+0.02 S c_{c}{ }^{-10}}\right)\left(\frac{S c_{c}}{1+S c_{c}}\right)\right. \\
\left.+\left(\frac{d_{32}}{h}\right)^{10}\right]+14
\end{gathered}
$$

where $\mathrm{h}$ is the height of column (where the samples are taken) in the packed column. The Peclet number, Schmidt number, and Reynolds number are calculated by Eqs. (16), (17), (18), respectively.

$$
\begin{aligned}
P e & =\text { Re.Sc } \\
S c & =\frac{\mu_{c}}{\rho_{c} D_{c}} \\
R e & =\frac{\rho_{c} V_{\text {slip }} d_{32}}{\mu_{c}}
\end{aligned}
$$

where $\mu_{c}$ is the continuous phase viscosity, $\rho_{c}$ continuous phase density and $V_{\text {slip }}$ slip velocity calculated by Eq. (19).

$$
V_{\text {slip }}=\left[\frac{Q_{c}}{A \varepsilon(1-\varphi)}\right]+\left[\frac{Q_{d}}{A \varepsilon \varphi}\right]
$$

The results were obtained from Eq. (15), and the experimental Sherwood numbers were compared, and the outcomes of the comparison are summarized in Table 3 . The first series of the experiments (1-36) were carried out with the nozzle $1 \mathrm{~mm}$, and the second series (37-72) were carried out with the nozzle $2.5 \mathrm{~mm}$.

The average values of the absolute relative error for Eq. (1), Eq. (2), and Eq. (15) were obtained at 82\%, 70.18\%, and 8.04\%, respectively.

The comparison between the average absolute value of relative errors \% AARE shows that Eq. (15) is less different from RahbarKelishami and Bahmanyar (2012) model compared with Seibert and Fair (1988) model, due to consideration of the column height effect (parameter h) in the proposed correlation to calculate Sherwood number of the continuous phase.

The comparison of Sherwood with experimental results, calculated using the proposed correlation, is displayed in Fig. 9, indicating that the proposed correlation can make a highly accurate estimate for the

\begin{tabular}{|c|c|c|c|c|c|c|c|}
\hline Exp No. & Experimental $\mathrm{Sh}_{\mathrm{c}}$ & Seibert $\mathrm{Sh}_{\mathrm{c}}$ & Seibert ARE & Rahbar $\mathrm{Sh}_{\mathrm{c}}$ & Rahbar ARE & Proposed Model Sh & Proposed Model ARE \\
\hline 1 & 38.79365 & 88.39749 & 1.278659 & 55.31538 & 0.425888 & 38.73912 & 0.001406 \\
\hline 2 & 26.92857 & 76.21451 & 1.830247 & 35.0904 & 0.303092 & 28.23115 & 0.048372 \\
\hline 4 & 297.9246 & 168.2277 & 0.435335 & 285.2291 & 0.042613 & 296.0930 & 0.006148 \\
\hline 5 & 168.1238 & 142.5598 & 0.152055 & 223.6201 & 0.330092 & 166.4271 & 0.010092 \\
\hline 7 & 49.63492 & 97.33834 & 0.961086 & 65.37550 & 0.317127 & 49.26879 & 0.007376 \\
\hline 8 & 40.47619 & 89.92503 & 1.221677 & 55.81385 & 0.378930 & 40.33158 & 0.003573 \\
\hline 9 & 32.32143 & 81.53543 & 1.522643 & 41.92545 & 0.297141 & 32.32312 & 0.000052 \\
\hline 10 & 506.5143 & 195.6256 & 0.613781 & 343.0358 & 0.322752 & 507.8509 & 0.002639 \\
\hline 14 & 53.84921 & 95.71366 & 0.777439 & 69.06729 & 0.282606 & 47.34683 & 0.120752 \\
\hline 15 & 38.57143 & 84.73410 & 1.196810 & 48.38243 & 0.254359 & 35.19193 & 0.087617 \\
\hline 16 & 762.8127 & 214.0257 & 0.719426 & 425.4575 & 0.442252 & 708.4833 & 0.071222 \\
\hline
\end{tabular}
continuous phase Sherwood number.

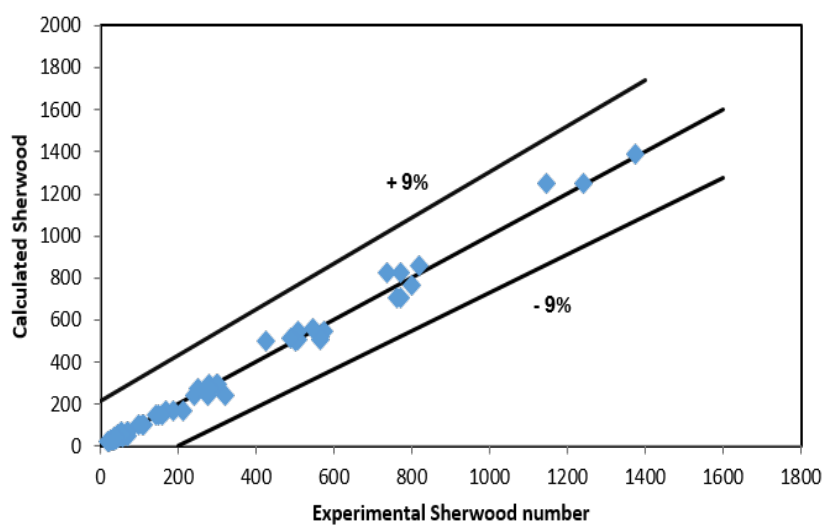

Fig. 9. Comparison of experimental results with calculated values by the proposed model.

Table 3 Comparison of experimental Sherwood of continuous phase with proposed model. 


\begin{tabular}{|c|c|c|c|c|c|c|c|}
\hline 17 & 426.3762 & 194.6702 & 0.543431 & 371.2301 & 0.129337 & 503.2320 & 0.180253 \\
\hline 18 & 249.8222 & 164.1186 & 0.343059 & 272.0642 & 0.089031 & 272.6599 & 0.091416 \\
\hline 19 & 53.84683 & 110.6561 & 1.055016 & 87.74089 & 0.629453 & 71.20189 & 0.322304 \\
\hline 20 & 44.52381 & 99.67958 & 1.238793 & 74.36560 & 0.670243 & 52.83379 & 0.186641 \\
\hline 21 & 35.01190 & 89.51680 & 1.556753 & 55.53043 & 0.586044 & 40.04045 & 0.143624 \\
\hline 22 & 1147.211 & 249.5213 & 0.782497 & 499.9056 & 0.564243 & 1250.660 & 0.090175 \\
\hline 23 & 735.5556 & 222.8322 & 0.697056 & 427.3184 & 0.419054 & 825.5969 & 0.122413 \\
\hline 24 & 509.1429 & 199.0704 & 0.609009 & 369.9250 & 0.273436 & 548.5951 & 0.077488 \\
\hline 25 & 38.23413 & 88.39749 & 1.312005 & 77.98300 & 1.039618 & 38.73912 & 0.013208 \\
\hline 26 & 28.63095 & 76.21451 & 1.661962 & 53.62467 & 0.872961 & 28.23115 & 0.013964 \\
\hline 27 & 20.91270 & 67.19167 & 2.212960 & 33.88106 & 0.620119 & 22.89944 & 0.095002 \\
\hline 28 & 280.3095 & 168.2277 & 0.399850 & 354.8838 & 0.266043 & 296.0931 & 0.056308 \\
\hline 29 & 187.9810 & 142.5598 & 0.241626 & 280.6839 & 0.493151 & 166.4272 & 0.114659 \\
\hline 30 & 109.9508 & 123.1367 & 0.119925 & 206.7358 & 0.880258 & 102.2590 & 0.069956 \\
\hline 31 & 50.89683 & 97.33834 & 0.912464 & 90.09909 & 0.77023 & 49.26879 & 0.031987 \\
\hline 32 & 47.15476 & 89.92503 & 0.907019 & 78.58333 & 0.666498 & 40.33158 & 0.144698 \\
\hline 33 & 34.28571 & 81.53543 & 1.378117 & 61.85658 & 0.804150 & 32.32312 & 0.057242 \\
\hline 34 & 565.0286 & 195.6256 & 0.653777 & 424.5044 & 0.248703 & 507.8518 & 0.101193 \\
\hline 35 & 276.1825 & 159.5826 & 0.422184 & 308.1075 & 0.115594 & 244.6313 & 0.114241 \\
\hline 36 & 143.8492 & 137.2424 & 0.045929 & 239.0588 & 0.661871 & 145.6146 & 0.012272 \\
\hline 37 & 61.52381 & 102.1830 & 0.660870 & 104.9513 & 0.705864 & 56.39295 & 0.083396 \\
\hline 38 & 60.87302 & 95.71366 & 0.572350 & 94.54536 & 0.553157 & 47.34683 & 0.222203 \\
\hline 39 & 38.18571 & 84.73410 & 1.219000 & 69.63316 & 0.823540 & 35.19193 & 0.078401 \\
\hline 40 & 772.4381 & 214.0257 & 0.722922 & 523.7705 & 0.321926 & 708.5022 & 0.082771 \\
\hline 41 & 502.7095 & 194.6702 & 0.612758 & 458.4608 & 0.088021 & 503.2369 & 0.001049 \\
\hline 42 & 275.7778 & 164.1186 & 0.404888 & 339.0284 & 0.229354 & 272.6601 & 0.011305 \\
\hline 43 & 70.65873 & 110.6561 & 0.566064 & 117.0353 & 0.656345 & 71.20189 & 0.007687 \\
\hline 44 & 50.00000 & 99.67958 & 0.993592 & 100.9265 & 1.018530 & 52.83379 & 0.056676 \\
\hline 45 & 36.63095 & 89.51680 & 1.443748 & 78.24200 & 1.135953 & 40.04045 & 0.093077 \\
\hline 46 & 1240.128 & 249.5213 & 0.798794 & 613.4335 & 0.505347 & 1250.706 & 0.008530 \\
\hline 47 & 772.2222 & 222.8322 & 0.711440 & 526.0117 & 0.318834 & 825.6069 & 0.069131 \\
\hline 48 & 576.0000 & 199.0704 & 0.654392 & 456.8889 & 0.206790 & 548.5981 & 0.047573 \\
\hline 49 & 39.53968 & 88.39749 & 1.235665 & 128.4181 & 2.247828 & 38.73912 & 0.020247 \\
\hline 50 & 32.19048 & 76.21451 & 1.367610 & 94.86313 & 1.946932 & 28.23115 & 0.122997 \\
\hline 51 & 21.03571 & 67.19167 & 2.194171 & 67.66520 & 2.216682 & 22.89944 & 0.088598 \\
\hline 52 & 302.5198 & 168.2277 & 0.443912 & 509.8646 & 0.685392 & 296.3473 & 0.020404 \\
\hline 53 & 211.8095 & 142.5598 & 0.326943 & 407.6501 & 0.924607 & 166.4591 & 0.214109 \\
\hline 54 & 109.4643 & 123.1367 & 0.124903 & 305.7824 & 1.793444 & 102.2599 & 0.065815 \\
\hline 55 & 52.57937 & 97.33834 & 0.851265 & 145.1087 & 1.759803 & 49.26879 & 0.062963 \\
\hline 56 & 56.26190 & 89.92503 & 0.598329 & 129.2451 & 1.297204 & 40.33158 & 0.283146 \\
\hline 57 & 36.25000 & 81.53543 & 1.249253 & 106.2031 & 1.929740 & 32.32312 & 0.108328 \\
\hline 58 & 490.0571 & 195.6256 & 0.600811 & 605.7709 & 0.236123 & 510.4679 & 0.041650 \\
\hline 59 & 321.3889 & 159.5826 & 0.503460 & 445.4276 & 0.385946 & 244.7238 & 0.238543 \\
\hline 60 & 158.2341 & 137.2424 & 0.132663 & 350.3090 & 1.213865 & 145.6214 & 0.079710 \\
\hline 61 & 62.73016 & 102.1830 & 0.628930 & 165.5684 & 1.639375 & 56.39295 & 0.101023 \\
\hline
\end{tabular}




\begin{tabular}{lllllllll}
62 & 70.238100 & 95.71366 & 0.362703 & 151.2337 & 1.153158 & 47.34683 & 0.325909 \\
\hline 63 & 42.428570 & 84.73410 & 0.997100 & 116.9157 & 1.755590 & 35.19193 & 0.170561 \\
\hline 64 & 801.31430 & 214.0257 & 0.732907 & 742.5155 & 0.073378 & 765.8082 & 0.044310 \\
\hline 65 & 565.95710 & 194.6702 & 0.656034 & 652.5476 & 0.152998 & 518.3352 & 0.084144 \\
\hline 66 & 283.88890 & 164.1186 & 0.421892 & 488.0229 & 0.719063 & 273.0739 & 0.038096 \\
\hline 68 & 68.222220 & 110.6561 & 0.621995 & 182.2148 & 1.670901 & 71.20189 & 0.043676 \\
\hline 69 & 55.952380 & 99.67958 & 0.781507 & 160.0240 & 1.860004 & 52.83379 & 0.055736 \\
\hline 70 & 39.666670 & 89.5168 & 1.256726 & 128.7749 & 2.246426 & 40.04045 & 0.009423 \\
\hline 72 & 1375.1670 & 249.5213 & 0.818552 & 866.0313 & 0.370235 & 1387.423 & 0.008913 \\
\hline$\% A A R E$ & 817.77780 & 222.8322 & 0.727515 & 745.6029 & 0.088257 & 855.8180 & 0.046517 \\
\hline
\end{tabular}

\section{CONCLUSIONS}

Three different concentrations of nanoparticles solution were used to investigate the influence of nanoparticles on the mass transfer rate in a packed column. Two factors, namely the internal circulation and the surface area of drops, were found to affect the changes of mass transfer coefficient versus droplet diameter. As the drops diameter increases, the internal circulations intensified, and as a result, the mass transfer rate is improved. The mass transfer coefficient decreases with the mean diameter of the drop because the total surface area available for mass transfer decreases due to increased volume of all drops. Therefore, the changes of mass transfer coefficient versus the mean droplet diameter depend on the result of one of these two factors. An increase of the droplet diameter increases the mass transfer coefficient as far as the total surface area of mass transfer does not decrease due to the increased volume of all drops.

The addition of nanoparticles to the dispersed phase beyond a critical concentration increases the efficiency of the mass transfer. The critical concentration in a nozzle with a hole-diameter of $1 \mathrm{~mm}$ was found as 0.05 vol. \%, leading to an enhanced extraction efficiency of $30 \%$. By the adding nanoparticles to the dispersed phase to a certain concentration, the extraction efficiency is declined by the occurrence of an agglomeration phenomenon, i.e., a change of the mass transfer mechanism from turbulence to diffusion as the nanoparticles accumulate. In a nozzle with a $2.5 \mathrm{~mm}$ hole-diameter, critical levels were not found. By the addition of nanoparticles up to 0.01 vol. \%, the mass transfer coefficient increased and enhanced the extraction efficiency to $36 \%$.

Many models are available to predict the mass transfer coefficient of the continuous phase; the cyclic drop models presented more accurate results than the static drop model. In the experimental work, by increasing the rotation in the drops, because of adding nanoparticles, the experimental data were extracted and the proposed model is based on these data with good accuracy.

\section{ACKNOWLEDGEMENTS}

The experiments were carried out, as the first author was a Master student at University of Tehran. The literature survey, evaluations, analysis and paper writing were carried out at Lund University.

\section{NOMENCLATURE}

a specific surface area $\left(\mathrm{m}^{3} / \mathrm{m}^{2}\right)$

A surface area $\left(\mathrm{m}^{2}\right)$

$\mathrm{C}_{\mathrm{d}}{ }^{*} \quad$ solute concentration in the dispersed phase in equilibrium with

$\mathrm{C}_{\mathrm{d}} \quad$ continuous phase $\left(\mathrm{kmol} / \mathrm{m}^{3}\right)$

$\mathrm{C}_{\mathrm{c}}^{*} \quad$ solute concentration in the continuous phase in equilibrium with dispersed phase $\left(\mathrm{kmol} / \mathrm{m}^{3}\right)$
$\mathrm{C}_{0} \quad$ initial concentration of solute in the continuous phase

$\quad\left(\mathrm{kmol} / \mathrm{m}^{3}\right)$

C solute concentration in the dispersed phase at the specified

height $\left(\mathrm{kmol} / \mathrm{m}^{3}\right)$

$\mathrm{C}_{\mathrm{c}} \quad$ solute concentration in the continuous phase at the specified

height $\left(\mathrm{kmol} / \mathrm{m}^{3}\right)$

$\mathrm{d}_{\mathrm{d}} \quad$ drop diameter $(\mathrm{m})$

$\mathrm{d}_{32} \quad$ Sauter mean diameter of drop (m)

d nozzle diameter (m)

D diffusion coefficient $\left(\mathrm{m}^{2} / \mathrm{s}\right)$

$\mathrm{h} \quad$ height of column (m) (getting sample)

$K_{d} \quad$ mass transfer coefficient based on dispersed phase $(\mathrm{m} / \mathrm{s})$

$\mathrm{K}_{\mathrm{c}} \quad$ mass transfer coefficient based on continuous phase $(\mathrm{m} / \mathrm{s})$

L dynamic column height (m)

$\mathrm{n}$ number of droplets

$\mathrm{N} \quad$ total number of experiment

$\mathrm{Q}_{\mathrm{d}} \quad$ flow rate of continuous phase $(\mathrm{mL} / \mathrm{min})$

$\mathrm{Q}_{\mathrm{c}} \quad$ flow rate of continuous phase $(\mathrm{mL} / \mathrm{min})$

$\mathrm{t} \quad$ mean rising time (s)

$\mathrm{V}_{\text {slip }} \quad$ slip velocity $(\mathrm{m} / \mathrm{s})$

$\mathrm{V}_{\mathrm{c}} \quad$ continuous phase velocity

$V_{d} \quad$ dispersed phase velocity

$\mathrm{v}_{\mathrm{c}} \quad$ continuous phase volume

$\mathrm{v}_{\mathrm{d}} \quad$ dispersed phase volume

Greek letters

$\mu_{\mathrm{c}} \quad$ continuous phase viscosity $(\mathrm{kg} / \mathrm{m} \mathrm{s})$

$\mu_{\mathrm{d}} \quad$ dispersed phase viscosity $(\mathrm{kg} / \mathrm{m} \mathrm{s})$

$\rho_{\mathrm{c}} \quad$ continuous phase density $\left(\mathrm{kg} / \mathrm{m}^{3}\right)$

$\rho_{\mathrm{d}} \quad$ dispersed phase density $\left(\mathrm{kg} / \mathrm{m}^{3}\right)$

$\gamma \quad$ interfacial tension $(\mathrm{N} / \mathrm{m})$

$\varphi \quad$ dynamic holdup

$\varepsilon \quad$ porous media

Group

$\operatorname{Re} \quad$ Reynolds number $\left(\operatorname{Re}=\frac{\rho_{c} V_{S l i p} d_{32}}{\mu_{c}}\right)$

$\mathrm{Sc}_{\mathrm{c}} \quad$ Schmidt number $\left(\mathrm{Sc}_{\mathrm{c}}=\frac{\mu_{\mathrm{c}}}{\rho_{\mathrm{c} \mathrm{D}_{\mathrm{c}}}}\right)$

Pe Peclet number $(\mathrm{Pe}=\mathrm{Re} . \mathrm{Sc})$

$\mathrm{Sh}_{\mathrm{c}} \quad$ continuous phase Sherwood number $\left(\mathrm{Sh}_{\mathrm{c}}=\frac{\mathrm{K}_{\mathrm{c}} \mathrm{d}_{32}}{\mathrm{D}_{\mathrm{c}}}\right)$

\section{REFERENCES}

Amani P, Amani M, Saidur R, Yan WM. Hydrodynamic performance of a pulsed extraction column containing $\mathrm{ZnO}$ nanoparticles: drop size and size distribution. Chemical Engineering Research and Design. 2017 May 1;121:275-86.

https://doi.org/10.1016/j.cherd.2017.03.017 
Annesini MC, Marrelli L, Piemonte V, Turchetti L. Artificial organ engineering. Berlin, Germany: Springer; 2017.

Ashrafmansouri SS, Esfahany MN. The influence of silica nanoparticles on hydrodynamics and mass transfer in spray liquidliquid extraction column. Separation and Purification Technology. 2015 Sep 4;151:74-81.

Ashrafmansouri SS, Willersinn S, Esfahany MN, Bart HJ. Influence of silica nanoparticles on mass transfer in a membrane-based microcontactor. RSC Advances. 2016;6(23):19089-97.

Ashrafmansouri SS, Nasr Esfahany M. Mass transfer into/from nanofluid drops in a spray liquid-liquid extraction column. AIChE Journal. 2016 Mar;62(3):852-60.

https://doi.org/10.1002/aic.15084

Azimi N, Rahimi M, Khodaei MM, Roshani M, Karami E, Ebrahimi E, Mohammadi F. Intensification of liquid-liquid extraction in a tubular sono-extractor using $1.7 \mathrm{MHz}$ ultrasound and $\mathrm{SiO} 2$ nanoparticles. Chemical Engineering and Processing-Process Intensification. 2019 Mar 1;137:28-38.

https://doi.org/10.1016/j.cep.2019.01.014

Bahmanyar A, Khoobi N, Mozdianfard MR, Bahmanyar H. The influence of nanoparticles on hydrodynamic characteristics and mass transfer performance in a pulsed liquid-liquid extraction column. Chemical Engineering and Processing: Process Intensification. 2011 Nov 1;50(11-12):1198-206.

https://doi.org/10.1016/j.cep.2011.08.008

Bahmanyar A, Khoobi N, Moharrer MM, Bahmanyar H. Mass transfer from nanofluid drops in a pulsed liquid-liquid extraction column. Chemical Engineering Research and Design. 2014 Nov 1;92(11):231323.

https://doi.org/10.1016/i.cherd.2014.01.024

Baird MH, Hamielec AE. Forced convection transfer around spheres at intermediate Reynolds numbers. The Canadian Journal of Chemical Engineering. 1962 Jun;40(3):119-21.

https://doi.org/10.1002/cjce.5450400307

Brauer H, Mewes D. Stoffaustausch einschließlich chemischer Reaktionen. Sauerländer; 1971.

Chen H, Yang W, He Y, Ding Y, Zhang L, Tan C, Lapkin AA, Bavykin DV. Heat transfer and flow behaviour of aqueous suspensions of titanate nanotubes (nanofluids). Powder Technology. 2008 Mar 18;183(1):63-72.

https://doi.org/10.1016/i.powtec.2007.11.014

Choi SU, Singer DA, Wang HP. Developments and applications of non-Newtonian flows. ASME FED. 1995 Nov 12;66:99-105.

Clift R, Grace JR, Weber ME. Bubbles, Drops and Particles. Dover Publications. 1978.

Das SK, Putra N, Thiesen P, Roetzel W. Temperature dependence of thermal conductivity enhancement for nanofluids. Journal of Heat Transfer. 2003 Aug 1;125(4):567-74.

https://doi.org/10.1115/1.1571080

Dharmaiah G, Baby Rani CH, Vedavathi N, Balamurugan KS. Heat and mass transfer on mhd fluid flow over a semi infinite flat plate wth radiation absorption, heat source and diffusion thermo effect. Frontiers in Heat and Mass Transfer (FHMT). 2018 Apr 21;11. http://dx.doi.org/10.5098/hmt.11.6

Dillon H, Doherty P, Roberts J. Experimental validation of natural convection in a rectangle using schlieren imaging. Frontiers in Heat and Mass Transfer (FHMT). 2017 Aug 19;9(1).

http://dx.doi.org/10.5098/hmt.9.1

Eckert ER, Sakamoto H, Simon TW. The heat/mass transfer analogy factor, $\mathrm{Nu} / \mathrm{Sh}$, for boundary layers on turbine blade profiles. International Journal of Heat and Mass Transfer. 2001 Mar 1:44(6), 1223-33.

https://doi.org/10.1016/S0017-9310(00)00175-7

Fang X, Xuan Y, Li Q. Experimental investigation on enhanced mass transfer in nanofluids. Applied Physics Letters. 2009 Nov 16;95(20):203108.

ttps://doi.org/10.1063/1.3263731

Ganvir RB, Walke PV, Kriplani VM. Heat transfer characteristics in nanofluid-A review. Renewable and Sustainable Energy Reviews. 2017 Aug 1;75:451-60.

https://doi.org/10.1016/j.rser.2016.11.010

Gerardi C, Cory D, Buongiorno J, Hu LW, McKrell T. Nuclear magnetic resonance-based study of ordered layering on the surface of alumina nanoparticles in water. Applied Physics Letters. 2009 Dec 21;95(25):253104.

https://doi.org/10.1063/1.3276551

Garg P, Alvarado JL, Marsh C, Carlson TA, Kessler DA, Annamalai $K$. An experimental study on the effect of ultrasonication on viscosity and heat transfer performance of multi-wall carbon nanotube-based aqueous nanofluids. International Journal of Heat and Mass Transfer. 2009 Oct 1;52(21-22):5090-101.

https://doi.org/10.1016/j.ijheatmasstransfer.2009.04.029

Griffith RM. Mass transfer from drops and bubbles. Chemical Engineering Science. 1960 Jun 1;12(3):198-213. https://doi.org/10.1016/0009-2509(60)85006-3

Hashem MA, Aimaghrabi MN. Modelling Mass Transfer Coefficients During Drop Formation. Journal of Engineering Science \& Technology Review. 2013 Jan 1;6(1).

Hatami A, Bastani D, Najafi F. Investigation the effect of super hydrophobic titania nanoparticles on the mass transfer performance of single drop liquid-liquid extraction process. Separation and Purification Technology. 2017 Apr 4;176:107-19.

https://doi.org/10.1016/j.seppur.2016.11.063

Hayworth CB, Treybal RE. Drop formation in two-liquid-phase systems. Industrial \& Engineering Chemistry. 1950 Jun;42(6):117481.

https://doi.org/10.1021/ie50486a030

Jang SP, Choi SU. Role of Brownian motion in the enhanced thermal conductivity of nanofluids. Applied Physics letters. 2004 May 24;84(21):4316-8.

https://doi.org/10.1063/1.1756684

Kang YT, Kim JK. Comparisons of mechanical and chemical treatments and nano technologies for absorption applications. HVAC\&R Research. 2006 Aug 1;12(S2):807-19.

Kim JK, Jung JY, Kang YT. The effect of nano-particles on the bubble absorption performance in a binary nanofluid. International Journal of Refrigeration. 2006 Jan 1;29(1):22-9. 
Krishnamurthy S., Bhattacharya P., Phelan P.E., Prasher R.S., 2006. Enhanced mass transport in nanofluids. Nano Letters, 6(3) 419-42. https://doi.org/10.1021/nl0522532

Lee JW, Jung JY, Lee SG, Kang YT. CO2 bubble absorption enhancement in methanol-based nanofluids. International Journal of Refrigeration. 2011 Dec 1;34(8):1727-33.

https://doi.org/10.1016/j.ijrefrig.2011.08.002n

Lochiel AC, Calderbank PH. Mass transfer in the continuous phase around axisymmetric bodies of revolution. Chemical Engineering Science. 1964 Jul 1;19(7):471-84.

https://doi.org/10.1016/0009-2509(64)85074-0

Lu S, Xing M, Sun Y, Dong X. Experimental and theoretical studies of $\mathrm{CO} 2$ absorption enhancement by nano-Al2O3 and carbon nanotube particles. Chin. J. Chem. Eng.. 2013 Sep;21(9):983-90.

https://doi.org/10.1016/S1004-9541(13)60550-9

Manikandan S, Karthikeyan N, Suganthi KS, Rajan KS. Enhancement of volumetric mass transfer coefficient for oxygen transfer using Fe2O3-water nanofluids. Asian Journal of Scientific Research. 2012;5(4):271-7.

DOI: 103923/ajsr.2012

Moghadam EH, Bahmanyar H, Heshmatifar F, Ziaei-Azad H. The investigation of mass transfer coefficients in a pulsed regular packed column applying SiO2 nanoparticles. Separation and Purification Technology. 2017 Apr 4;176:15-22.

https://doi.org/10.1016/j.seppur.2016.11.044

Mohammad S. Effects of variable viscosity on heat and mass transfer by mhd mixed convection flow along a vertical cylinder embedded in a non-darcy porous medium. Frontiers in Heat and Mass Transfer (FHMT). 2020 Feb 27;14.

http://dx.doi.org/10.5098/hmt.14.7

Naleini N, Rahimi M, Heydari R. Oleuropein extraction using microfluidic system. Chemical Engineering and Processing: Process Intensification. 2015 Jun 1;92:1-6.

https://doi.org/10.1016/j.cep.2015.03.023

Nematbakhsh G, Rahbar-Kelishami A. The effect of size and concentration of nanoparticles on the mass transfer coefficients in irregular packed liquid-liquid extraction columns. Chemical Engineering Communications. 2015 Nov 2;202(11):1493-501.

Olle B, Bucak S, Holmes TC, Bromberg L, Hatton TA, Wang DI. Enhancement of oxygen mass transfer using functionalized magnetic nanoparticles. Industrial \& Engineering Chemistry Research. 2006 Jun 7;45(12):4355-63.

https://doi.org/10.1021/ie051348b

Prasher R. Brownian-motion-based convective-conductive model for the thermal conductivity of nanofluids. InASME 2005 Summer Heat Transfer Conference collocated with the ASME 2005 Pacific Rim Technical Conference and Exhibition on Integration and Packaging of MEMS, NEMS, and Electronic Systems 2005 Jan 1 (pp. 343-353). American Society of Mechanical Engineers.

https://doi.org/10.1115/HT2005-72048

Rafiei V, Safdari J, Moradi S, Mallah MH. Mass transfer studies in an L-shaped pulsed sieve-plate extraction column. Separation Science and Technology. 2018 Nov 22;53(17):2756-68.

https://doi.org/10.1080/01496395.2018.1472613
Rahbar-Kelishami A, Bahmanyar H. New predictive correlation for mass transfer coefficient in structured packed extraction columns. Chemical Engineering Research and Design. 2012 May 1;90(5):61521.

https://doi.org/10.1016/j.cherd.2011.09.004

Rezamohammadi A, Bahmanyar H, Najafabadi MS, Rouzbahani MG. Investigation of characteristic velocity in a pulsed packed column in the presence of $\mathrm{SiO} 2$ nanoparticles. Chemical Engineering Research and Design. 2015 Feb 1;94:494-500.

https://doi.org/10.1016/j.cherd.2014.09.007

Saien J, Hasani R. Hydrodynamics and mass transfer characteristics of circulating single drops with effect of different size nanoparticles. Separation and Purification Technology. 2017 Mar 24;175:298-304.

Saien J, Daneshamoz S. Compensating effect of ultrasonic waves on retarding action of nanoparticles in drops liquid-liquid extraction. Ultrasonics sonochemistry. 2018 Mar 1;41:514-20. https://doi.org/10.1016/j.ultsonch.2017.10.016

Seibert AF, Fair JR. Hydrodynamics and mass transfer in spray and packed liquid-liquid extraction columns. Industrial \& Engineering Chemistry Research. 1988 Mar;27(3):470-81.

https://doi.org/10.1021/ie00075a017

Veilleux J, Coulombe S. A total internal reflection fluorescence microscopy study of mass diffusion enhancement in water-based alumina nanofluids. Journal of Applied Physics. 2010 Nov 15;108(10):104316.

https://doi.org/10.1063/1.3514138

Weber ME. Mass transfer from spherical drops at high Reynolds numbers. Industrial \& Engineering Chemistry Fundamentals. 1975 Nov;14(4):365-6.

https://doi.org/10.1021/i160056a016

Wen D, Ding Y. Experimental investigation into convective heat transfer of nanofluids at the entrance region under laminar flow conditions. International Journal of Heat and Mass Transfer. 2004 Nov 1;47(24):5181-8.

https://doi.org/10.1016/j.ijheatmasstransfer.2004.07.012

Xuan Y, Roetzel W. Conceptions for heat transfer correlation of nanofluids. International Journal of Heat and Mass Transfer. 2000 Oct 1;43(19):3701-7.

https://doi.org/10.1016/S0017-9310(99)00369-5

Yang Y, Zhang ZG, Grulke EA, Anderson WB, Wu G. Heat transfer properties of nanoparticle-in-fluid dispersions (nanofluids) in laminar flow. International Journal of Heat and Mass Transfer. 2005 Mar 1;48(6):1107-16.

https://doi.org/10.1016/j.ijheatmasstransfer.2004.09.038

Zarei MJ, Gholizadeh F, Sabbaghi S, Keshavarz P. Estimation of CO2 mass transfer rate into various types of Nanofluids in hollow Fiber membrane and packed bed column using adaptive neuro-fuzzy inference system. International Communications in Heat and Mass Transfer. 2018 Aug 1;96:90-7.

https://doi.org/10.1016/j.icheatmasstransfer.2018.05.022

Zhu D, Li X, Wang N, Wang X, Gao J, Li H. Dispersion behavior and thermal conductivity characteristics of Al2O3-H2O nanofluids. Current Applied Physics. 2009 Jan 1;9(1):131-9.

https://doi.org/10.1016/i.cap.2007.12.008 